https://doi.org/10.48009/1_iis_2005_211-217

\title{
LIFELONG E-LEARNING: A FOUNDATION FOR TECHNOLOGY EDUCATION AND PROFESSIONAL SUCCESS
}

\author{
L. Roger Yin, University of Wisconsin-Whitewater, yinl@uww.edu \\ Tena B. Crews, University of South Carolina, tcrews@sc.edu \\ Robert G. Brookshire, University of South Carolina, brookshire@sc.edu \\ Daniel T. Norris, University of South Carolina, dnorris@gwm.sc,edu
}

\begin{abstract}
The set of skills and the environment in which our graduates work demand that they keep pace with technological advances and practice continuous professional development and lifelong learning. This paper presents three techniques for the inculcation and practice of lifelong learning for information technology professionals: problem-based learning, self-assessment, and electronic portfolios. We characterize the combination of these practices as "e-learning."
\end{abstract}

Keywords: lifelong learning, problem-based learning, self-assessment, electronic portfolio, elearning

Wisdom is not a product of schooling, but the lifelong attempt to acquire it. - Albert Einstein

\section{INTRODUCTION: LEARNING TO LEARN}

The goal of information technology education is to develop graduates who have a broad set of skills. They must be able to elucidate the needs and goals of their clients-organizations, information systems stakeholders, and information systems users. They must identify and analyze organizational, workgroup, and individual problems and opportunities. Our graduates must be able to stratify information technology solutions that enable their clients to meet their needs and goals by solving their problems and taking advantage of their opportunities. Information technology graduates must be able to develop software, implement networks and databases, integrate software and hardware products, and deliver technical training and documentation. They must be able to maintain and support intricate information systems to deliver value to clients. These activities are characterized by a high degree of complexity, the absence of a single right answer or set of answers, the application of a variety of potential methodologies and approaches, and a continuously evolving business and technological environment.

Learning takes time, and it won't happen simply because instructions are given [8]. The set of skills and the environment in which our graduates work demand that they keep pace with technological advances and practice continuous professional development and lifelong learning. Ultimately, they should be learning how to learn new skills built upon the prior knowledge they possess. The process of building expertise solidifies an effective approach in designing professional training curricula (see Figure 1). This paper presents several techniques that promote this practice. The combination of these techniques we call "e-learning." 


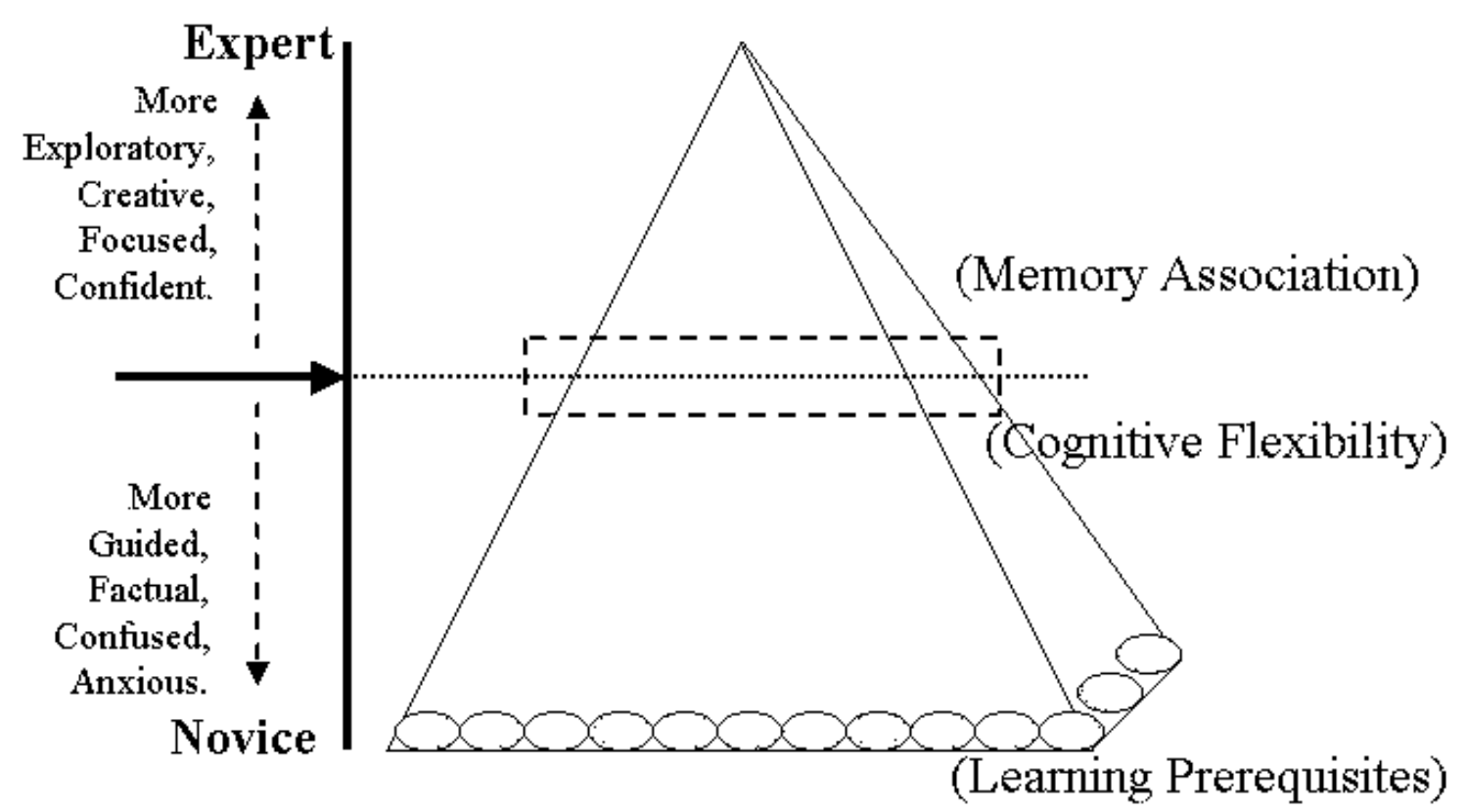

Figure 1. Learning Pyramid

\section{LIFELONG LEARNING AND TECHNOLOGY EDUCATION}

Because the field of information technology is so dynamic, it is critical that we prepare our graduates to become lifelong learners. Lifelong learning is characterized by the learner's ability to assess his or her own competencies. Lifelong learning is not dichotomized, spatially and temporally, into a place and time to acquire knowledge (school) and a place and time to apply knowledge (the workplace). Information technology has become so knowledge-intensive and fluid in content that learning has become an integral and inseparable part of work activities. Professional work can no longer proceed from a fixed educational background; rather, education must be smoothly incorporated as part of work activities, fostering growth and exploration. Similarly, students require educational tools and environments whose aim is to help cultivate the desire to learn and create, and not simply to communicate subject matter divorced from meaningful and personalized activity.

Lifelong learning is a continuous engagement in acquiring and applying knowledge and skills in the context of authentic, self-directed problems. The theoretical framework for lifelong learning is grounded in descriptive and prescriptive goals such as: (a) learning should take place in the context of authentic, complex, and often ill-structured problems; (b) learning should be embedded in the pursuit of intrinsically rewarding activities; (c) learning-on-demand needs to be supported because change is inevitable, complete coverage is impossible, and obsolescence is unavoidable; (d) organizational and collaborative learning must be supported because the individual human mind is limited; and (e) an inquiring mind that constantly asks "why" must be developed.

Lifelong learning is not a new concern in our schools and society. Hasan and Wagner [4] noted that schools must not only provide the opportunity to learn fundamental knowledge and skills, but also engage the desire to continue to learn. To achieve this, curricula and assessment techniques need to be revised, and teachers need to be involved in continuing education to learn 
how to integrate these features appropriately. Students must learn skills and be able to understand how to transfer and build upon those skills to continue their learning in other classes and the workplace.

To stimulate lifelong learning, technology education must emulate the work environment in which graduates will find themselves. In other words, we as technology educators should conduct each of our classes as if we are leading an IT/IS consulting team, treat the students as junior consultants, and hence help them to conduct themselves as young professionals even before graduation [7]. Problem-based learning is one instructional approach that focuses on this objective.

\section{ALIGNING INSTRUCTION AND ASSESSMENT IN PROBLEM-BASED LEARING}

Problem-based learning [1] is common in professional education, such as medicine, law, teacher education, and business, and is becoming increasingly common in pre-college education. As the label implies, problem-based learning is an educational approach where an ill-structured problem initiates learning. Problem-based learning is necessarily interdisciplinary. By addressing realworld problems, students are required to cross traditional disciplinary boundaries in their problem-solving quest. Problem-based learning is particularly appropriate for teaching information technology, as our field is characterized by problem solving.

The primary characteristic of problem-based learning is that the instructional unit or activity is anchored in an authentic, ill-structured problem. That is, the information easily available to the students is not sufficient to solve the problem; a single, correct process for solving the problem is not readily apparent or does not exist; and the problem may change as the students attempt to solve it. During problem-based learning, the teacher generally serves as a facilitator or "metacognitive coach" [4]. Student choices promote ownership of learning, thinking and procedural skills training is available as needed, and social interaction and collaboration are required to solve the problem.

A major weakness of historical and contemporary problem-based learning efforts is the lack of formal student evaluation and influence in course design [3]. Indeed, assessment of student progress is often haphazard or non-existent. When assessment is formally planned, it often does not align well with the objectives of the problem-based learning that preceded it. Incorporating both formative and summative problem-based assessments is crucial to the success of a problembased learning activity, however. We suggest the following strategies for aligning instruction with assessment in problem-based learning:

1. Stress that students are professionals in the field in which the ill-structured problem exists and therefore the teacher should assess students as if he or she were their supervisor. Having students operate as professionals in the field in which the ill-structured problem arises increases student enthusiasm and ownership of learning.

2. If instruction is problem-based, assessment should be similarly structured. If students are asked in the course of a unit to solve ill-structured problems through hands-on activities, the assessment should include how well they complete that task. This is not to say an evaluation of their ability to learn the factual and foundational information important to solving the problem should not be completed. Rather, an interdisciplinary, real world and hands-on approach to learning should be evaluated largely in the same manner it is taught. 
3. Provide reasonable guidelines regarding your expectations for the students. There will be more than one correct answer. Teachers engaged in problem-based learning instruction should present their expectations for students before the unit begins so the students will understand their goals and how their progress will be assessed. A grading rubric should be used that outlines the expectations with the students first, becoming an effective, flexible evaluation tool.

4. Do not postpone assessment until the end of the activity or unit; model real-world behavior, in which ongoing assessment occurs. The emphasis on the use of factual knowledge in conjunction with real world problem solving skills makes problem-based learning an advantageous approach to teaching and assessment. The teacher should provide periodic feedback. When providing such feedback, it is important to think about the source of feedback, the recipients of feedback, the mode of feedback, the content of feedback, and the occasion of feedback: the who, how, what, and when [6]. This permits the teacher to act as a facilitator, asking guiding questions that allow students to approach a solution or solutions to the problem at hand.

Lifelong learners must be able to evaluate their own competencies if they are to assess their educational needs. Self-assessment is not something that comes naturally, however; it must be taught just like other skills.

\section{TEACHING SELF ASSESSMENT AS PREPARATION FOR LIFELONG LEARNING}

Involving students in the assessment and evaluation process is an essential part of balanced assessment. When students become active participants in the learning process, they gain a better sense of themselves as problem solvers, readers, writers, and thinkers. As students reflect on what they have learned and on how they learn, they develop the tools to become more effective learners. This assessment may be completed in an individual self-assessment or as an initial peer evaluation that leads to self-assessment.

Students must examine their work and think about what they do well and in which areas they still need help. To guide students in understanding the process of self-evaluation, they may use learning logs, interviews, and think-alouds [2]. Students may also complete a self-reflection/selfassessment sheet to help them learn more about themselves.

Once students have reflected on their learning, they are ready to set new goals for themselves. As they work toward these goals, they should be encouraged to reflect on their learning journey at regular intervals. Students may record their observations during these periods of self-reflection to help reaffirm their goals and motivate them to move toward meeting each goal. With practice, students who self-assess become more conscious learners, able to apply knowledge of their learning needs and styles to new areas of study. As students become more active participants in the assessment process, they will begin to evaluate their strengths and attitudes, analyze their progress in a particular area, and set goals for future learning.

Self-assessment can take many forms, including

- writing conferences

- whole-class or small-group discussion 
- reflection logs

- weekly self-evaluations

- self-assessment checklists and inventories

- peer conferences

- teacher-student interviews

These types of self-assessment share a common theme: Students review their work to determine what they have learned and what areas of confusion still exist. Although each method differs slightly, all should include enough time for students to consider thoughtfully and evaluate their progress. When students understand the criteria for good work before they begin an activity, they are more likely to meet those criteria. The key to this understanding is to make the criteria clear. As students evaluate their work, teachers may ask them to establish their own assessment criteria. Students may develop their own rubrics for guidance in and evaluation of their work. It is important to help students clarify their own criteria as they assess themselves.

Self-assessment alone will not insure success in lifelong learning. Technology professionals must develop a track record as evidence of educational and professional accomplishment so that external audiences can appreciate their achievements. An electronic portfolio is a valuable tool to provide this documentation.

\section{ELECTRONIC PORTFOLIO AND CAREER TRACKING}

Electronic portfolios are selective and purposeful collections of learners' work. Portfolios may include learners' reflections on their own work. They are records of a learning history that includes growth and change. They provide meaningful documentation of learners' abilities. Electronic portfolios provide information to learners, teachers, and other stakeholders such as employers about what students have learned or are able to do.

Portfolios bring together curricula, instruction, and self, peer, and teacher assessments. Through the use of portfolios teachers and learners can develop a shared understanding of what constitutes quality work and acquire a common language for evaluating learners' accomplishments.

Electronic portfolios foster active learning. Students become active learners when they assume ownership and control of their learning. Portfolios help learners set goals for learning, review their goals periodically, and assume responsibility for their own learning. Electronic portfolios encourage learners to engage in periodic self reflection, a very important component of learning. They also motivate learners. Displaying their work for anyone to review is more motivating for students than producing documentation for the teacher alone.

Electronic portfolios are instruments of feedback. They allow for evaluation of the efficiency of learning goals, the effectiveness of learning strategies, and the clarity of knowledge presentation. This leads to a system of feedback where several processes in the educational cycle may be evaluated simultaneously. Electronic portfolios are instruments of discussion of student performance. They serve as concrete instruments for discussion among learners, teachers, and other stakeholders. It is possible to gain a better understanding of students' abilities by examining their work. 
Electronic portfolios exhibit "benchmark" performance. Electronic portfolios provide an efficient method for displaying work that meets high standards. No longer is student performance behind classroom doors, but out in the public for all stakeholders to examine.

Electronic portfolios can store a variety of media. Samples of oral presentations, data flow diagrams or UML models, interface designs, and animations can be collected and displayed via electronic portfolios. This allows students to demonstrate a wide range of work. Because they are digital, electronic portfolios are easy to revise. The organization and content of electronic portfolios may be periodically updated. As learners progress though their school and work careers, new work may be added to the portfolios. The dynamic nature of electronic portfolios makes it possible to cross-reference student work in a meaningful way. Projects that involve multiple stages prior to the final product can also be presented in an electronic portfolio to show the steps in the solution of a problem, not just the final product.

\section{CONCLUSION: LIFELONG E-LEARNING}

This paper has presented three techniques for the inculcation and practice of lifelong learning for information technology professionals: problem-based learning, self-assessment, and electronic portfolios. We characterize the combination of these practices as e-learning. E-learning is an appropriate term because it describes the context, information technology education and professional development, and the techniques, which integrate technology with both formal and informal learning. Professionals in information technology must apply diverse sets of skills in continually shifting environments. This demands the constant evaluation of competencies and the acquisition of new knowledge, skills, and abilities. Graduates who practice the techniques we recommend here will have the foundation for lifelong e-learning.

In the world of technology, the high end is no end. The same principle should also apply to our desire and curiosity to learn. Lifelong e-learning is a self-driven commitment to continual professional development with the help of information technologies. Hence, if we encourage our students to practice effective lifelong e-learning, it should provide the blueprint for a lifetime of professional success.

\section{REFERENCES}

1. Bigelow, J. D. (October 2004). Using problem-based learning to develop skills in solving unstructured problems. Journal of Management Education, 28(5), 591.

2. Carr, S. C. (January 2002). Assessing learning processes: Useful information for teachers and students. Intervention in School \& Clinic, 37(3), 156-162.

3. Dolmans, D.H.J.M., Schmidt, H.G. \&Gijselaers, W.H. (1994). Use of student-generated learning issues to evaluate problems in a problem-based curriculum. Teaching and Learning in Medicine, 6, 199-202.

4. Gallagher, S., Stepien, W. J. \& Sher, B. T. (March 1995). Implementing problem-based learning in science classrooms. School Science and Mathematics, 95, 136-46.

5. Hansan, A. and Wagner, A. (April-May 1996). The school of the future. OECD Observer, 199, 6-9.

6. Rucker, M. L. \& Thomson, S. (September 2003). Assessing students learning outcomes: An investigation of the relationship among feedback measures. College Student Journal, 37(3), 400-404. 
7. Yin, L.R. \& Lien, H.N. (2005). Rethinking Organizational and End-user Information Systems Curriculum and Research: Issues, Challenges, and Opportunities. Information Technology, Learning, and Performance Journal (forthcoming).

8. Yin, L.R. (2001). Dynamic Learning Patterns: Temporal characteristics demonstrated by the learner. Journal of Educational Multimedia and Hypermedia, 10(3), 273-284. 